\title{
Aspectos da organização do trabalho e os distúrbios osteomusculares: um estudo com trabalhadores em instituições de longa permanência de idosos
}

\author{
Organizational aspects of the work and \\ musculoskeletal disorders: a study of workers from \\ elderly long term permanence institutions
}

\author{
Maria do Carmo Baracho de Alencar ${ }^{1}$, Janaína Bússola Montrezor ${ }^{2}$
}

\begin{abstract}
ALENCAR, M. C. B.; MONTREZOR, J. B. Aspectos da organização do trabalho e os distúrbios osteomusculares: um estudo com trabalhadores em instituições de longa permanência de idosos. Rev. Ter. Ocup. Univ. São Paulo, v. 21, n. 1, p. 15-22, jan./abr. 2010.

RESUMO: Este estudo exploratório teve o objetivo de investigar com base nas percepções dos trabalhadores e nas análises das atividades de trabalho, as relações existentes entre os distúrbios osteomusculares dos trabalhadores que cuidam/assistem os idosos e aspectos da organização do trabalho, em duas Instituições de Longa Permanência de Idosos, na cidade de Santos-SP. Os materiais e métodos consistiram de seleção de trabalhadores que assistiam/cuidavam diretamente de idosos; elaboração de questionário contendo dados demográficos e perguntas relacionadas ao trabalho, entre outras; o instrumento Questionário de Sintomas Osteomusculares- QNSO, levantamentos de tarefas e observações sistemáticas das atividades de trabalho com base na Ergonomia; sendo selecionadas para as observações: o banho, a troca de fraldas, transferências e deslocamentos dos idosos; e como complementos entrevistas semi-abertas gravadas junto aos trabalhadores com dores osteomusculares nos últimos 30 dias. Participaram do estudo 50 trabalhadores, com idade entre 21 e 66 anos; e destes 76,0\% relataram dores osteomusculares nos últimos 30 dias, sendo a região lombar a mais acometida. Em ambas as instituições foram identificadas sobrecargas físicas e desgaste mental; e relacionadas a alguns aspectos da organização do trabalho, conforme a percepção de alguns trabalhadores. Este estudo ressalta a importância dos aspectos organizacionais e psicossociais nos sintomas osteomusculares dos trabalhadores.
\end{abstract}

DESCRITORES: Distúrbios osteomusculares. Organização do trabalho. Condições do trabalho. Assistência/cuidado ao idoso. Terapia ocupacional.

\footnotetext{
1 Profa. Dra. do Departamento de Ciências da Saúde da Universidade Federal de São Paulo/ Campus da Baixada Santista.

${ }^{2}$ Acadêmica (Iniciação Científica) do curso de Terapia Ocupacional da Universidade Federal de São Paulo/ Baixada Santista.

Endereço para correspondência: Maria do Carmo Baracho de Alencar. Rua Prof. Torres Homem, 675, apto.72. Aparecida Santos, SP. CEP: 11.025.021. e.mail: belinha.alencar1@gmail.com
} 


\section{INTRODUÇÃO}

spectos da Organização do Trabalho
influenciam na saúde dos trabalhadores
contemporâneos. O conceito de Organização do Trabalho é bastante amplo, sendo que para Dejours (1992) compreende a divisão do trabalho, o conteúdo da tarefa, o sistema hierárquico, as modalidades de comando, as relações de poder, as questões de responsabilidades, entre outros. A Organização do Trabalho influencia o planejamento do trabalho, a execução das tarefas, e permeia todas as etapas do processo produtivo; determinando segundo Abrahão e Torres (2004) o que vai ser feito, como, quando e com que equipamentos/instrumentos; em que tempo, com que prazos, em que quantidade, com que qualidade, enfim, constituindose na "viga central da produção".

O trabalho implica em tarefa e atividade, sendo a tarefa o que é prescrito para ser feito, e a atividade o que é efetivamente realizado pelo trabalhador ao executar a tarefa. Para Guérin et al. (1997) a atividade de trabalho é uma estratégia de adaptação à situação real de trabalho, havendo uma distância entre o que é prescrito para fazer e o real (realidade do "fazer"). Dejours (1992) cita que trabalhar impõe-se aos trabalhadores por meio do imprevisto e do inesperado, que foge ao que está prescrito, caracterizando o âmbito do trabalho real. Dejours (2005) cita que a atividade real contém reajustes, rearranjos dos modos operatórios na tentativa de se aproximar das exigências impostas pela tarefa. Nesta distância emergem em geral conflitos internos e externos ao trabalhador, e questões que envolvem a saúde mental.

Entre os modelos teóricos que estudam saúde mental e trabalho está a Ergonomia, de caráter interdisciplinar; especialmente a Ergonomia de corrente francesa que privilegia a análise do trabalho. Na Ergonomia de corrente francesa, o resultado da atividade de trabalho é sempre única, singular; cujas características dependem das condições e organização do trabalho, tarefas a serem executadas, entre outros fatores; e também do trabalhador que executa as tarefas (com sua experiência profissional, seus modos operatórios, etc). A análise da atividade de trabalho está no centro da intervenção ergonômica; para Daniellou (2004) analisa os comportamentos, condutas, processos cognitivos e as interações realizadas por um trabalhador, durante as observações.

O trabalho também é uma atividade humana capaz de gerar um significado ao ser humano e é um dos alicerces da constituição do sujeito e de sua rede de significados (CODO et al., 1993; JARDIM; LANCMAN, 2009). Este significado para Codo et al. (1993) compreende o controle do trabalhador sobre seu trabalho, a importância social do trabalho, as relações sociais de produção, o sentido do trabalho, sua satisfação e seu comprometimento, entre outros.

Dejours (1992) cita que a insatisfação em relação ao conteúdo significativo do trabalho engendra um sofrimento cujo ponto de impacto é antes de tudo, mental. A forma que o trabalho é realizado permite a percepção da atividade como significativa ou não, influenciando no sentido único que ela assume para cada sujeito, emergindo sentimentos de prazer e sofrimento no trabalho (DEJOURS et al., 1994; FERREIRA; MENDES, 2001); sendo esta uma abordagem do modelo teórico da Psicodinâmica do Trabalho. A desarmonia entre o trabalho prescrito e o trabalho real pode gerar predomínio de vivências de sofrimento. Dejours et al. (1994) cita que o sofrimento ocasiona um sentimento de desprazer e tensão; e Brant e Minayo-Gomez (2004) citam que existem várias formas de expressar o sofrimento, como pela fala, corpo, atos, gestos, no trabalho.

Para Dejours (1992), esse sofrimento se manifestaria quando a realização da tarefa não representa nenhum sentido ao trabalhador. Codo et al. (1993) citam que este sofrimento advém de sentimentos gerados por diversos aspectos que atingem a organização em todos os contextos, e estão entre eles: sentimento de indignidade, de inutilidade, de desqualificação. Diferentes formas de adoecimento no trabalho emergem de respostas que o ser humano dá aos sofrimentos, conflitos, desafios e contradições a que é submetido (MENDES; CRUZ, 2004).

Os distúrbios osteomusculares relacionados ao trabalho (DORT), para Couto et al. (1998) se caracterizam por transtornos funcionais, mecânicos e lesões de músculos, tendões, fáscias, nervos, entre outros, que resultam em fadiga, queda da performance no trabalho, incapacidade temporária, entre outros. Segundo o Ministério da Saúde (2006) são caracterizados por sintomas como dor, parestesia, sensação de peso e fadiga; e de aparecimento insidioso.

Ghisleni e Merlo (2005) citam que os trabalhadores apontaram fatores organizacionais como um dos principais responsáveis pelo desenvolvimento de LER/DORT (Lesões por esforços repetitivos-LER). $\mathrm{O}$ fato de que a organização dos processos de trabalho, nos quais os trabalhadores estão inseridos, produz graves conseqüências à saúde do trabalhador também é citado por Merlo e Lápis (2007). A presença de distúrbios osteomusculares é comum em profissionais de enfermagem e é relatada por vários autores (MUROFUSE; MARZIALE, 2005; GURGUEIRA et al. 2003; MAGNANO et al., 2007), e em cuidadores de idosos (RADOVANIC; ALEXANDRE, 2004).

O objetivo deste estudo foi o de investigar com 
base nas percepções dos trabalhadores e nas análises das atividades de trabalho, as relações existentes entre os distúrbios osteomusculares dos trabalhadores que cuidam/ assistem os idosos e aspectos da organização do trabalho, em duas Instituições de Longa Permanência de Idosos.

\section{MATERIAIS E MÉTODOS}

Este estudo é exploratório e descritivo. Participaram deste estudo duas Instituições da cidade de Santos -SP, sendo uma filantrópica e outra particular. Foram posteriormente selecionados trabalhadores, tendo como critério de seleção o fato de atuarem junto aos idosos em atividades de trabalho (banho, troca de fraldas, entre outras). Este estudo teve a aprovação do Comitê de Ética em Pesquisa da Universidade Federal de São Paulo (n. 0310/09).

Foram realizadas duas etapas. Na primeira etapa elaborou-se um questionário a ser aplicado sob forma de entrevista junto aos trabalhadores, contendo: dados demográficos (idade, gênero, escolaridade), e perguntas relacionadas ao trabalho, incluindo as tarefas percebidas como a de maior dificuldade (quanto ao esforço físico). Aplicou-se ainda, o Instrumento Nórdico de Sintomas Osteomusculares-QNSO (PINHEIRO et al., 2002), com questões adicionais. Na segunda etapa, realizou-se levantamento de tarefas e observações sistemáticas das atividades de trabalho dos trabalhadores da equipe de enfermagem, exceto enfermeiros; com base na Ergonomia (GUÉRIN et al., 1997). Foram selecionadas para as observações as tarefas de transferências/movimentações dos idosos, o banho e a troca de fraldas, de forma sistemática; tarefas percebidas pelos trabalhadores como de maior dificuldade (dado obtido em questionário inicial aplicado). As observações ocorreram por um período aproximado de 2,5 meses para cada Instituição.

Como complementos, ainda foram selecionados 12 trabalhadores entre os observados para entrevistas semiabertas, sendo 05 da instituição "A" e 07 da "B", que apresentaram dores osteomusculares nos últimos 30 dias. As entrevistas foram gravadas e transcritas.

O estudo apresenta dados quantitativos e qualitativos. Ao final do estudo, para cada uma das duas instituições estudadas, foram apresentados os dados aos trabalhadores, e após discussões e concordância quanto aos levantamentos obtidos, sugestões foram propostas em conjunto com os trabalhadores, e posteriormente entregue aos gestores.

\section{RESULTADOS E DISCUSSÃO}

As Instituições eram uma filantrópica (denominada no estudo de Instituição “A”), e a outra particular (denominada no estudo de Instituição "B"). A Instituição "A", apresentava 48 idosos institucionalizados de ambos os gêneros. Destes idosos, 40 eram totalmente cuidados/ assistidos por 9 trabalhadores de enfermagem (enfermeiro, técnicos e auxiliares de enfermagem), e a Instituição "B", era uma instituição particular que possuía 121 idosos. Destes idosos, 58 eram totalmente cuidados/assistidos por 51 trabalhadores (enfermeiros, técnicos e auxiliares de enfermagem, e cuidadores de idosos). Os demais idosos eram independentes nas atividades de vida diária.

Os turnos de trabalho aconteciam de um modo geral no esquema de 12 horas por 36 horas (trabalhavam um dia e folgavam no outro), com direito a uma folga ao mês, em ambas as Instituições. Os dados demográficos gerais, de profissão registrada, tempo de serviço e número de idosos cuidados/assistidos nas Instituições "A" e "B" encontramse na Tabela 1.

A Tabela 1 mostra que nas duas instituições ("A" e "B") o gênero feminino foi mais prevalente entre os trabalhadores, uma prevalência de escolaridade em segundo grau; ainda uma prevalência de tempo de serviço inferior à 5 anos. A tabela 1 também mostra a relação de trabalhadores por quantidade de idosos cuidados/assistidos/dia nas tarefas selecionadas, havendo uma relação menor entre o número de trabalhadores e idosos diretamente assistido-cuidados na instituição "A" (filantrópica).

\section{Os sintomas osteomusculares}

Do número total de trabalhadores $76,0 \%$ relataram dores osteomusculares nos últimos 30 dias, sendo que $54,0 \%$ também relataram dores nos últimos 7 dias, demonstrando uma alta prevalência de sintomas dolorosos osteomusculares entre os trabalhadores. As regiões mais acometidas nos últimos 30 dias foram em: 44,0\% em região lombar, $34,0 \%$ região cervical, $22,0 \%$ em região de ombros, $14,0 \%$ em região de quadril, $6,0 \%$ em punhos/mãos, entre outras regiões; havendo mais de uma região acometida por alguns trabalhadores. Estudos como os de Gurgueira et al. (2003) e Murofuse e Marziale (2005) também apontaram as regiões de coluna lombar, coluna cervical e ombros, como as regiões dolorosas mais atingidas pelos trabalhadores de enfermagem. O número total de afastamentos registrados por causa das dores osteomusculares nos últimos 12 meses foi de 12,0\% entre os entrevistados. Em estudo de Gurgueira et al. (2003) a dor lombar demonstrou ser uma das maiores causas de absenteísmo e de procura médica entre os trabalhadores. 
ALENCAR, M. C. B.; MONTREZOR, J. B. Aspectos. Rev. Ter. Ocup. Univ. São Paulo, v. 21, n. 1, p. 15-22, jan./abr. 2010.

Tabela 1 - Dados demográficos gerais, de profissão registrada, tempo de serviço e número de idosos assistidos nas Instituições “A” e "B"

\begin{tabular}{|c|c|c|}
\hline Instituição & "A" & "B" \\
\hline Quantidade de Trabalhadores & 9 & 41 \\
\hline Gênero & $\begin{array}{l}\text { Feminino } \mathrm{n}=08 \\
\text { Masculino } \mathrm{n}=01\end{array}$ & $\begin{array}{l}\text { Feminino } \mathrm{n}=40 \\
\text { Masculino } \mathrm{n}=01\end{array}$ \\
\hline Faixa Etária & De 30 a 58 anos de idade & De 21 a 66 anos de idade \\
\hline Escolaridade & $\begin{array}{l}1^{\circ} \text { Completo/Incompleto } \mathrm{n}=01 \\
2^{\circ} \text { Completo/Incompleto } \mathrm{n}=06 \\
\text { Superior } \mathrm{n}=02\end{array}$ & $\begin{array}{l}1^{\circ} \text { Completo/Incompleto } \mathrm{n}=02 \\
2^{\circ} \text { Completo/Incompleto } \mathrm{n}=35 \\
\text { Superior } \mathrm{n}=02 \\
\text { Superior Incompleto } \mathrm{n}=02\end{array}$ \\
\hline Profissão registrada & $\begin{array}{l}\text { Técnicos de Enfermagem } \\
\mathrm{n}=06 \\
\text { Auxiliares de Enfermagem } \\
\mathrm{n}=02 \\
\text { Enfermeiro } \mathrm{n}=01\end{array}$ & $\begin{array}{l}\text { Técnicos de Enfermagem } \\
\mathrm{n}=02 \\
\quad \text { Auxiliares de Enfermagem } \\
\mathrm{n}=31 \\
\text { Enfermeiro } \mathrm{n}=01 \\
\text { Cuidadores de Idosos } \mathrm{n}=07\end{array}$ \\
\hline Tempo de Serviço & $\begin{array}{l}\text { Menos de } 1 \text { ano } n=01 \\
\text { De } 1 \text { à } 5 \text { anos } n=4 \\
5 \text { anos ou mais anos } n=04\end{array}$ & $\begin{array}{l}\text { Menos de } 1 \text { ano } n=20 \\
\text { De } 1 \text { à } 5 \text { anos } n=12 \\
5 \text { anos ou mais anos } n=09\end{array}$ \\
\hline $\begin{array}{l}\text { Idosos assistidos/ } \\
\text { cuidados/dia nas tarefas selecionadas }\end{array}$ & 40 & 58 \\
\hline
\end{tabular}

\section{As tarefas e turnos de trabalho}

As tarefas dos trabalhadores nas Instituições "A" e "B" envolviam: dar e/ou supervisionar o banho dos idosos, incluindo: vestimenta e higiene pessoal dos mesmos; preparar e dar as medicações, servir o café da manhã, trocar fraldas e servir o almoço, servir o café da tarde, e servir o jantar, realizar as verificações de pressão arterial e glicemia quando necessário (na "A" estas tarefas ocorria eventualmente, e na " $\mathrm{B}$ " diariamente), entre outras; havendo algumas diferenciações conforme as categorias profissionais: entre auxiliares de enfermagem, técnicos de enfermagem e enfermeiros (estes eram os supervisores), não analisados neste estudo. Trabalhavam em geral em turnos 12 x 36h, com uma folga ao mês (com exceção dos enfermeiros), e em turnos diurno e noturno de segunda a segunda. Foram selecionadas para as observações as tarefas de dar banho, trocar fraldas, transferências e deslocamentos dos idosos.

\section{Os depoimentos e as atividades de trabalho}

Em observações tanto durante as atividades de banho, troca de fraldas, transferências e deslocamentos dos idosos (transferências: cama-cadeira de rodas, cadeira de rodascadeira de banho, etc; e deslocamentos: quarto-refeitório, quarto-banheiro, e vice-versa, etc.), foram observadas exigências físicas e repetitividade de movimentos em ambas as Instituições, sendo mais frequentes na Instituição "A". No banho os trabalhadores permaneciam grande parte do tempo na frente do idoso e com flexão do tronco, e esta tarefa era realizada muitas vezes por um único trabalhador e com controle de tempo, para dar conta de dar o banho entre o período do café da manhã e almoço; além de haver transferências e deslocamentos dos idosos precedentes até a chegada ao banheiro. O ritmo de trabalho variava conforme a quantidade de idosos e o número de trabalhadores para a tarefa, que compreendia também a escovação dos dentes (nem sempre realizada), e fazer a barba nos homens (quando necessário), e posterior secagem e vestimenta.

A troca de fraldas era realizada nos períodos do dia, uma logo após o banho, e à tarde, sendo executada em geral por dois trabalhadores, mas de modo individualizado selecionando os setores. Essas trocas nos idosos que alcançavam algum ortostatismo eram feitas no banheiro 
com estes idosos segurando em barras nas paredes; ou nas camas havendo ou não transferências e deslocamentos precedentes. Posturas inadequadas com flexão e rotação (torção) do tronco foram observadas, e aspectos como o ritmo de trabalho acelerado foram evidenciados como geradores de sobrecargas físicas, aliado ao pouco ou nenhum estímulo motor junto aos idosos. O não estímulo motor junto aos idosos além de poder agravar a saúde dos mesmos, também podem aumentar a sobrecarga física e desgaste no trabalho. Alexandre (1998) cita quanto aos fatores de risco relacionados aos distúrbios osteomusculares, as posturas inadequadas, movimentos frequentes de flexão e torção da coluna vertebral, entre outros. As exigências físicas e repetitividade no trabalho, e outros fatores também foram evidenciados; como nos depoimentos:

“(...) o pior mesmo éo peso, pegar da cama, pôr na cadeira, tira da cadeira de banho, põe na cadeira de rodas, leva para o refeitório pra eles poderem almoçar.traz de novo pra cama..vai e volta...e na hora do banho, abaixa, ai quando chego em casa tomo medicação.. dói a minha coluna, dizem que é hérnia de disco..." (gênero feminino, 51 anos, técnica de enfermagem, instituição ' $A$ ').

“(...) leva pra lá..pra cá, traz e leva..também cansa um pouco as pernas, dá um dorzinha, e quando termina de colocar elas na cama, tô exausta!..eu venho e tomo um antiinflamatório, tomo um suco, alguma coisa.porque tá doendo legal..é um serviço bem pesado porque têm idosas que pesam 80, 70 quilos.." (gênero feminino, 54 anos, técnica de enfermagem, instituição " $A$ ")

O fator peso dos idosos foi um aspecto de risco para as dores osteomusculares, também encontrado em outros estudos (PARADA et al., 2002; GURGUEIRA et al., 2003). Em ambas as instituições havia dois setores, sendo um feminino (onde ficavam as idosas do gênero feminino) e outro masculino (onde ficavam os idosos do gênero masculino); só que em algumas atividades os trabalhadores na instituição "A" ficavam sozinhos ao executar algumas tarefas, e ainda ficavam responsáveis pelos dois setores, podendo influenciar no desgaste tanto físico quanto mental.

A falta de funcionários para as exigências de trabalho impostas foi um aspecto que surgiu nos depoimentos; como no depoimento:

“(...) é muito trabalho para pouco funcionário... já pedi ajudante, eles dizem que não tem condições de contratar ninguém... eu nunca tive ajudante... dois anos sozinho... eu tô com uma inflamação aguda na coluna na L3 - L4, e agora tá pegando aqui nos ombros, pra mim é bastante complicado... eu não tenho ajuda... já falei pra eles, mas... se não tá satisfeito, que peça as contas". (gênero masculino, 43 anos, técnico de enfermagem da instituição " $A$ ").

Notou-se um desgaste do trabalhador neste último depoimento, causado pela falta de escuta por parte da chefia imediata; o trabalhador expõe a problemática que nada é feito para resolver os seus problemas, e ainda que se ele não estiver satisfeito, que peça demissão; gerando constrangimento para o trabalhador. Os trabalhadores vêm se sujeitando às condições precárias do trabalho, muitas vezes por medo do desemprego. Melzer (2008) relata que situações de ameaça, constrangimentos na relação com chefes imediatos transformam o ambiente de trabalho em espaço de desconforto e sofrimento. O indivíduo (trabalhador) irá usar estratégias de defesa individuais ou coletivas para dar conta dos constrangimentos no trabalho, e este sofrimento pode ser criativo ou patológico, sendo um sofrimento patológico quando há falhas nas estratégias de defesa.

Dejours (2007) cita que "há efeitos dessa precarização do trabalho, que tem como consequência a estratégia defensiva do silêncio, da cegueira, da surdez"; e relata ainda como efeito de ameaça de demissão e precarização, o individualismo. Além disso, notou-se que os trabalhadores "suportam" muitas vezes as dores osteomusculares durante o trabalho, que são muitas vezes ignoradas pelos supervisores; quando informadas. Executar as tarefas com exigências físicas e presença de sintomas dolorosos, pode favorecer o agravamento do quadro clínico e o afastamento do trabalho.

Especialmente no banho, as exigências físicas durante as tarefas foram evidenciadas, em virtude da quantidade de idosos e tempo determinado para a realização das tarefas, pois tinham que dar conta de terminar o banho antes do horário previsto para almoço, ocasionando agravos para o surgimento das dores osteomusculares, como observado nos depoimentos:

“(...) às vezes já tô sentindo dor dando banho mesmo e no final do dia, a situação ainda tá pior. minha coluna tá queimando, além de doer e aí já tenho que tomar um comprimido para chegar bem em casa..e descansar para aquela dor melhorar.porque quando eu vim pra cá eu fiz exame médico, e desvio na coluna essas coisas eu não tenho nada. isso é causa de excesso mesmo do trabalho.." (gênero feminino, 42 anos, auxiliar de enfermagem, instituição "B") 
“(...) na hora dos banhos eu acho que a gente se sobrecarrega mais, porque você termina os banhos e já começa a sentir um monte de dor.às vezes durante o primeiro banho, e você já tá lá toda com dor. São muitos banhos..tem que fazer sozinha em 10, 12..sobrecarrega mesmo!" (gênero feminino, 29 anos, auxiliar de enfermagem, instituição " $B$ ")

$\mathrm{Na}$ instituição "B" os trabalhadores faziam rodízios em tarefas a cada mês, passando por trocas de setores de trabalho (ex. feminino, masculino, enfermaria, etc.), sendo intercalado entre alguns deles, as tarefas de maiores exigências físicas. Na instituição "A" não havia rodízio e os trabalhadores tinham que dar conta do trabalho, sem mudanças nas tarefas a serem executadas diariamente.

Para darem conta do trabalho, os trabalhadores acabavam por executar algumas tarefas "correndo" denotando um ritmo de trabalho acelerado (especialmente no banho e troca de fraldas), e que exigem muitas vezes que o trabalhador vá além das suas capacidades físicas. Além de ser exigida atenção durante essas tarefas, também deviam estar sempre disponíveis para outras situações "não prescritas", como no caso de algum idoso o chamar, solicitar ajuda (ex: solicitar um colírio, querer que sua pressão arterial seja aferida, querer trocar de ambiente - ir da sala de televisão para o pátio, entre outras); aumentando o desgaste mental. Em alguns depoimentos evidenciaramse essas situações, e a percepção de que o tempo não é suficiente para a realização adequada de algumas tarefas; como no depoimento:

“(...) tem que dar banho, fazer curativo, essas coisas todas, fazer a cama..chamam toda hora, ai tem que sair correndo, é colírio, é pressão, alguém passando mal..tem muita coisa pra fazer, e às vezes não dá tempo pra fazer porque não dá tempo! Eu acho que não tem tempo suficiente, não sei..pra fazer o que devia ser feito..." (gênero feminino, 51 anos, técnica de enfermagem da instituição " $A$ ")

A percepção do fato de não haver tempo suficiente para concluírem as tarefas adequadamente, e com responsabilidade por pessoas, são aspectos que podem acometer a saúde mental do trabalhador. Todo trabalho envolve algum investimento afetivo; e para VasquesMenezes (2002) há uma tensão gerada entre envolver-se afetivamente e não completar o circuito afetivo, e ainda ser incapaz de modificar as situações que se apresentam à sua frente. $\mathrm{O}$ fato não ter tempo suficiente para realizar as tarefas adequadamente de "assistência/cuidado" pode afetar as relações entre trabalhador-idoso. Lancman e Uchida (2003) citam que quando o trabalhador utiliza todos os seus recursos psico-afetivos para dar conta da atividade e demandas impostas, e percebe que nada pode fazer para se adaptar e/ou transformar o trabalho, é que surge o sofrimento.

Conflitos entre a chefia foram também encontrados em alguns depoimentos, como no depoimento abaixo: “(...) aqui da parte deles (chefia) ninguém se importa com você não...falta atenção deles com a gente, só vê se está fazendo seu serviço e pronto, ninguém se preocupa em como você está, se está bem ou não..." (gênero feminino, 29 anos, auxiliar de enfermagem da instituição " $B$ ").

A percepção de não atenção dada aos trabalhadores pode parecer entre outros, que há pouca valorização pelo que é feito, e pouco reconhecimento por parte de supervisores e gestores. O reconhecimento no trabalho é importante, e funciona em dois modos de registro: reconhecimento pela hierarquia (supervisores) e reconhecimento pelos pares. $\mathrm{O}$ primeiro para Dejours et al. (1994) é um reconhecimento da utilidade, e o segundo é um reconhecimento de habilidade, de inteligência, de talento pessoal, de originalidade. Esses dois reconhecimentos são importantes para a constituição da identidade, que se constitui no interjogo das relações sociais (LANCMAN; UCHIDA, 2003).

Outros aspectos não investigados também podem influenciar no surgimento de dores osteomusculares, como idade, obesidade, sedentarismo, alguns desvios posturais estruturais, entre outros não investigados neste estudo. Porém, questiona-se a pouca importância em geral que é dada em estudos relacionados aos distúrbios osteomusculares relacionados ao trabalho junto aos aspectos organizacionais, havendo nesta abordagem e com diferentes modelos teóricos, um grande campo de atuação e possibilidades de contribuições da Terapia Ocupacional em vários aspectos.

Aspectos organizacionais como poucos funcionários para a realização de algumas tarefas, obrigando os mesmos a realizar sozinho, e com divisão de tarefas inadequadas (por exemplo junto aos idosos mais pesados), ainda em ritmo acelerado, entre outras; expõem os trabalhadores aos riscos de afecções osteomusculares além de gerarem desgaste; desgaste que pode vir a gerar sofrimento. Ainda, más posturas ou até mesmo "descuidos posturais" e as próprias dores, podem também ser expressões de sofrimento no trabalho, não tirando das análises a importância das questões biomecânicas de risco também evidenciadas. É preciso compreender que o ser humano pode se expressar através de ações que envolvem movimentos no trabalho. Para Smith e Carayon (1996) quando as pessoas estão sob condições emocionais 
adversas, o nível de tensão muscular aumenta independente das exigências biomecânicas; e se estão bravas, este fato pode induzir a métodos impróprios no trabalho (na execução). Trudel (2004) também cita que características estruturais e psicossociais da organização do trabalho podem ativar mecanismos fisiológicos, no caso aumentar a tensão muscular e a secreção de hormônios.

\section{CONCLUSÕES FINAIS}

Em ambas as instituições foram identificadas sobrecarga física e desgaste; havendo aparentemente maiores sobrecargas físicas na instituição " $\mathrm{A}$ " (filantrópica) comparado com a "B" (particular). Os aspectos da organização do trabalho encontrados aumentaram as demandas físicas e mentais no trabalho, conforme a percepção de alguns trabalhadores, em ambas as instituições. Houve ainda outros fatores que interferiram nos quadros álgicos dos trabalhadores, como por exemplo, a altura das camas, o peso dos idosos e o espaço físico das instituições (distância entre os ambientes internos, para os deslocamentos).

Diante das condições e exigências impostas no trabalho, como se preocupar com "cuidados posturais"? Os trabalhadores se sujeitavam às exigências impostas, e executavam as tarefas muitas vezes com posturas inadequadas e uma "resistência à dor", em prol da garantia de emprego, entre outras; e o sintoma doloroso pareceu ser "banalizado" pelos supervisores e até mesmo pelos colegas, quando informado. Até que ponto o sofrimento estaria relacionado aos sintomas osteomusculares?

As percepções que os trabalhadores têm das exigências do trabalho enfatizaram a importância dos aspectos organizacionais e psicossociais no desenvolvimento dos distúrbios osteomusculares. Pesquisas futuras devem aprofundar as questões trazidas neste estudo.

ALENCAR, M. C. B.; MONTREZOR, J. B. Organizational aspects of the work and musculoskeletal disorders: a study of workers from elderly long term permanence institutions. Rev. Ter. Ocup. Univ. São Paulo, v. 21, n. 1, p. 15-22, jan./abr. 2010.

\begin{abstract}
This exploratory study had the objective of investigate with the worker's perceptions bases and activities analyses the relationship in between the musculoskeletal disorders of assistance/ care of aging workers and work organizational aspects in two long permanence of aging people institutions in Santos-SP city. The materials and methods consisted in workers' selection, elaboration of a questionnaire containing demographic data and questions related to the work and others; the Nordic Questionnaire for Musculoskeletal Disorder, survey of the tasks and systematic observations of activities; selection for observations: the bath, the diaper changes, transferences and transferring of the oldies; and as complements semi-open recorded interviews next to workers with pain in the last 30 days. Participated in this study 50 workers, with age in between 21 to 66 years old, and from these $76,0 \%$ related musculoskeletal pain in the last 30 days, with greatest commitment in the lower back region. In both Institutions were identified physical overload and mental consuming; and work organizational related aspects by some worker's perceptions in both institutions. This study highlights the importance of the organizational and psychosocial aspects in the work related musculoskeletal pain.
\end{abstract}

KEY WORDS: Musculoskeletal disorders. Work organization. Work conditions. Assistance/care of aging. Occupational therapy.

\title{
REFERÊNCIAS
}

1. ABRAHÃO, J. I.; TORRES, C. C. Entre a organização do trabalho e o sofrimento: o papel da mediação da atividade. Rev Produção, v. 14, n. 6, p. 67-76, 2004.

2. ALEXANDRE, N. M. C. Aspectos ergonômicos relacionados com o ambiente e equipamentos hospitalares. Rev. Latinoamer. Enf., v. 6, n. 4, p. 103-109, 1998.
3. BRANT, L. C.; MYNAIO-GOMEZ, C. A transformação do sofrimento em adoecimento: do nascimento da clínica à psicodinâmica do trabalho. Cien. Saúde Coletiva, v. 9, n. 1, p. 213-223, 2004.

4. BOTHA, W. E.; BRIDGER, R. S. Anthropometric variability, equipment usability and musculoskeletal pain in a group of 
nurses in the Western Cape. Appl. Ergon., v. 26, n. 6, p. 481-490, 1998.

5. CODO, W.; SAMPAIO, J.; HITOMI, C. Indivíduo, trabalho e sofrimento: uma abordagem interdisciplinar. Petrópolis: Vozes, 1993.

6. COUTO, H. A.; NICOletTI, S. J.; LECH, O. Como gerenciar a questão das LER/DORT: lesões por esforços repetitivos, distúrbios osteomusculares relacionados ao trabalho. Belo Horizonte: Ergo, 1998.

7. DANIELlOU, F. (org.). A ergonomia em busca de seus princípios: debates epistemológicos. São Paulo: Ed. Edgard Blucher, 2004.

8. DEJOURS, C. A loucura do trabalho. 5a ed. Cortez: São Paulo, 1992.

9. DEJOURS, C. O fator humano. Rio de Janeiro: FGV, 2005.

10. DEJOURS, C.;ABDOUCHELI, E.; JAYET, C. Psicodinâmica do trabalho: contribuições da escola dejouriana a análise da relação prazer, sofrimento e trabalho. São Paulo: Atlas, 1994.

11. DEJOURS, C. A banalização da injustiça social. Rio de Janeiro: FGV, 2007.

12. FERREIRA, M. C; MENDES, A. M. "Só de pensar em vir trabalhar, já fico de mau humor": atividade de atendimento ao público e prazer-sofrimento no trabalho. Estudos Psicol., v. 1, n. 1, p. 93-104, 2001.

13. GHISLENI, A. P; MERLO, A. R. C. Trabalhador contemporâneo e patologias por hipersolicitação. Psicol. Reflexão Crítica, v. 18, n. 2, p. 171-176, 2005.

14. GUÉRIN, F. ; LAVILlE, A.; DANIElloU, F.; DURAFFORG, J.; KERGUELEN, A. Compreender o trabalho para transformá-lo: a prática da ergonomia. São Paulo: Edgard Blucher, 1997. p. 13-16.

15. GURGUEIRA, G. P.; ALEXANDRE, N. M. C.; CORREA FILHO, H. P. Prevalência de sintomas músculo-esqueléticos em trabalhadores de enfermagem. Rev. Latinoamer. Enf., v. 11, n. 5, p. 608-613, 2003.

16. JARDIM, T. A.; LANCMAN, S. Aspectos subjetivos do morar e trabalhar na mesma comunidade: a realidade vivenciada pelo agente comunitário de saúde. Interface: Comunicação, Saúde e Educação, v. 13, n. 28, p. 123-135, 2009.

17. LANCMAN, S.; UCHIDA, S. Trabalho e subjetividade. Cad. Psicol. Social Trabalho, v. 6, p. 77-88, 2003.
18. MAGNANO, T. S. B. S.; LISBOA, M. T. L.; SOUZA, I. E. O.; MOREIRA, M. C. Distúrbios músculo-esqueléticos em trabalhadores de enfermagem: associação com condições de trabalho. Rev. Bras. Enf., v. 60, n. 6, p. 701-705, 2007.

19. MELZER, A. C. S. Aspectos da organização do trabalho e distúrbios osteomusculares: o caso dos trabalhadores das indústrias cerâmicas. Rev. Bras. Promoção Saúde, v. 21, n. 3, p. 161-166, 2008.

20. MENDES, A. M.; CRUZ, R. M. Trabalho e saúde no contexto organizacional. In: TAMAYO, A. (org). Cultura e saúde nas organizações. Porto Alegre: Artmed, 2004.

21. MERLO, A. R. C.; LAPIS, N. L. Saúde e os processos de trabalho no capitalismo: reflexões na interface da psicodinâmica do trabalho e da sociologia do trabalho. Psicol. Sociedade, v. 19, n. 1, 2007.

22. MINISTÉRIO DA SAÚDE. LER/DORT: protocolos de atenção integrada à saúde do trabalhador de complexidade diferenciada. Brasília, DF, 2006.

23. MUROFOSE, N. T.; MARZIALE, M. H. P. Doença do sistema osteomuscular em trabalhadores de enfermagem. Rev. Latinoamer. Enf., v. 13, n. 3, p. 364-373, 2005.

24. PARADA, E. O.; ALEXANDRE, N. M. C; BENATTI, M. C. C. Lesões ocupacionais afetando a coluna vertebral em trabalhadores de enfermagem. Rev. Latinoamer. Enf., v. 10, n. 1, p. 64-69, 2002.

25. PINHEIRO, F. A.; TRÓCCOLI, B. T.; CARVEL, C. V. Validação do questionário nórdico de sintomas osteomusculares como medida de morbidade. Rev. Saúde Pública, v. 36, p. 307-312, 2002.

26. RADOVANIC, C. A. T.; ALEXANDRE, N. M. C. validation of na instrument for patient handling assessment. Appl. Ergon., v. 35, p. 321-328, 2004.

27. SMITH, M. J.; CARAYON, P. Work organization, stress, and cumulative trauma disorders. In: MOON, S. D.; SAUTER, S. L. Beyond biomechanics: psychosocial aspects of musculoskeletal disorders in office work. London: Taylor \& Francis, 1996

28. TRUDEL, L. Meio psicossocial de trabalho e processos de adaptação e reabilitação. In: LANCMAN, S. (org). Saúde, trabalho e terapia ocupacional. São Paulo: Roca, 2004.

29. VASQUES-MENEZES, I. Saúde mental e trabalho: aplicações na prática clínica. In: JACQUES, M. G.; CODO, W. Saúde mental e trabalho: leituras. Petrópolis, RJ: Vozes, 2002. 